\title{
Once-Monthly Long-Acting Injectable Aripiprazole for the Treatment of Patients with Schizophrenia and Co-occurring Substance Use Disorders: A Multicentre, Observational Study
}

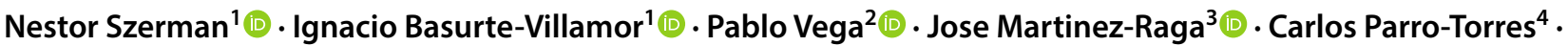 \\ Julia Cambra Almerge ${ }^{5}$ D Lara Grau-López $^{6}$ (D) $\cdot$ Mario De Matteis $^{4}$ (D) Francisco Arias $^{7}$ (D)
}

Published online: 5 February 2020

(c) The Author(s) 2020, corrected publication 2020

\begin{abstract}
Aim To evaluate the efficacy and impact of long-acting injectable (LAI) aripiprazole in patients with schizophrenia with a coexisting substance use disorder (SUD).

Patients and methods A multicenter, observational, descriptive and retrospective study was conducted in patients with a DSM-5 diagnosis of schizophrenia who had a coexisting SUD and were treated with LAI-aripiprazole. Disease severity was evaluated with the Clinical Global Impression (CGI) severity scale for schizophrenia, daily functioning and disability were evaluated with the World Health Organisation Disability Assessment Scale (WHODAS-2.0), and the severity of the addiction was evaluated with the Severity of Dependence Scale (SDS).

Results The sample included 40 patients. Overall, after 6 months of treatment with LAI-aripiprazole at a dose of $400 \mathrm{mg} / 4$ weeks in $77.5 \%$ of the patients, we observed significant improvement in the psychopathological symptoms, with a reduction of over $30 \%$ in the scores of the five CGI-severity scales. The WHODAS-2.0 mean (standard deviation) score was also significantly reduced from $57.6(8.2)$ to 42.3 (4.3) points $(p<0.001)$. Regarding SUDs, after 6 months of treatment, substance use was stopped in 5 of the 9 patients with cocaine use disorder and in 3 of the 16 patients with alcohol abuse disorder. A significant reduction in the severity of the dependence was observed only in the subgroups of participants with cocaine and alcohol use disorders.

Conclusion Our study suggests that once-monthly LAI-aripiprazole retains its antipsychotic efficacy in patients with schizophrenia and a coexisting SUD and could be useful for the management of cocaine or alcohol use disorders in this population.
\end{abstract}

Nestor Szerman

nszermanb@gmail.com

1 Instituto Psiquiatría y Salud Mental, Hospital General Universitario Gregorio Marañón, Calle de Lope de Rueda, 43, 28009 Madrid, Spain

2 Instituto de Adicciones, Madrid Salud, Madrid, Spain

3 Psychiatry Department, University Hospital Dr. Peset, University of Valencia and University CEU-UCH, Valencia, Spain

4 Psychiatry Department, Hospital General Universitario Gregorio Marañón, Madrid, Spain

5 Psychiatry Department, "Proyecto Hombre", Madrid, Spain

6 Addiction and Dual Diagnosis Unit, Department of Psychiatry, Vall d'Hebron University Hospital, CIBERSAM, Barcelona, Spain

7 Psychiatry Department, 12 de Octubre University Hospital, Madrid, Spain

\section{Key Points}

Once-monthly LAI, aripiprazole is efficacious for managing psychotic symptoms in patients with schizophrenia with coexisting substance use disorders.

In patients with psychosis and co-occurring alcohol or cocaine use disorder, LAI aripiprazole could be useful for reducing the severity of the use disorder and eventually for stopping consumption.

These promising results should be confirmed by randomized clinical trials that include a long-term followup and an evaluation of the impact of the treatment on specific outcomes, such as sustained abstinence and the so-called "good functioning". 


\section{Introduction}

Substance use disorders (SUDs) are common in patients with schizophrenia. A recent meta-analysis showed that the prevalence of any SUD among patients with schizophrenia or first-episode psychosis was $42 \%$, with the most common SUDs being those related to illicit drugs (28\%), cannabis (26\%), alcohol (24\%) and stimulants (7\%) [1]. The prevalence of tobacco smoking in patients with schizophrenia varies across countries, but overall, the rate of current schizophrenia patient smokers is up to 6-fold higher than the rate reported in the general population [2]. Although less studied, the prevalence of pathological gambling has been reported to be approximately $10 \%$ among patients with schizophrenia [3]. The presence of SUDs among patients diagnosed with schizophrenia is associated with a higher severity of symptoms, an increased risk of non-adherence, an increased risk of extrapyramidal symptoms, more frequent relapse and inpatient psychiatric admissions, and a higher occurrence of disruptive behaviors [4-11].

Treatment of patients with schizophrenia and a coexisting SUD is particularly challenging. According to current guidelines, the best treatment approach is the combination of antipsychotics and psychosocial interventions for addictive behaviors $[12,13]$. Although there are few advantages of one antipsychotic treatment over another, when treating patients with psychosis and coexisting SUDs, the use of secondgeneration antipsychotics may be preferred over first-generation antipsychotics due to their better tolerability profile, including a lower liability for inducing extrapyramidal side effects [12]. In addition, first-generation antipsychotics, due to potent dopaminergic blockade, can induce a worsening of craving, as reported with haloperidol and smoking [14].

Aripiprazole is an atypical antipsychotic that, in contrast to first-generation and other second-generation antipsychotics, acts as a partial agonist of D2 receptors, modulating their activity instead of blocking it [15]. Since aripiprazole is a partial agonist, it produces substantially less functional antagonism of $\mathrm{D} 2$ receptor-mediated neurotransmission than full antagonists [15]. Dopaminergic dysfunction is well known to be involved in addiction. Thus, drugs such as aripiprazole, which can modulate the dopaminergic system, might be beneficial for reducing craving, rewarding effects, and relapse [16]. These characteristics, together with its well-established efficacy for the treatment of schizophrenia, the lower risk of extrapyramidal side effects compared to first-generation antipsychotics, and the lower risk of metabolic side effects compared to most second-generation antipsychotics [17], make aripiprazole an attractive alternative for the treatment of patients with schizophrenia with coexisting SUDs. Evidence from randomized clinical trials and laboratory studies has suggested that oral aripiprazole could be efficacious for the management of alcohol $[18,19]$ or cocaine dependence [20,21]. However, other clinical [22] and laboratory studies [23-25] have reported negative results. Focusing on dual disorders, a randomized neuroimaging study suggested that oral aripiprazole combined with escitalopram may be useful for the treatment of patients with major depression and alcohol dependence [26]. Moreover, although published evidence on the efficacy of aripiprazole in patients with schizophrenia and co-occurrent SUDs is scarce, a randomized study comparing oral aripiprazole with perphenazine in a sample of patients with schizophrenia and cocaine dependence reported a reduction in cocaine craving associated with aripiprazole [27].

While highlighting the need for more research, partly due to the high level of noncompliance in dual disorder patients, some authors have proposed the preferred use of long-acting injectable (LAI) formulations in the management of patients with schizophrenia and a co-occurrent SUD [12, 13, 28]. In the case of LAI aripiprazole, to date, the published evidence is limited to a naturalistic trial that showed better outcomes with LAI aripiprazole than with LAI paliperidone in patients with comorbid psychosis and SUDs [29] and a small case series [30]. The aim of this retrospective study was to evaluate the efficacy and impact of long-acting injectable aripiprazole in patients with schizophrenia with a coexisting SUD.

\section{Patients and Methods}

This multicenter, observational, descriptive and retrospective study was conducted at five sites in Spain between October 2017 and February 2018; the five participant sites were Hospital Universitario Gregorio Marañón (Madrid, Spain). Instituto Adicciones (Madrid, Spain), Hospital Universitario Vall d'Hebron (Barcelona, Spain), Hospital Universitari Dr. Peset (Valencia, Spain), and Complejo Asistencial Universitario Salamanca (Salamanca, Spain). The study was revised and approved by the Ethics Committee of the Hospital General Universitario Gregorio Marañón (Madrid, Spain)(Protocol code: FPD-ARI-2017-01), and all patients gave their written informed consent for using their data with investigational purposes.

Patients with a diagnosis of schizophrenia and a coexisting SUD according to the DSM-5 who had received treatment with LAI aripiprazole were eligible for the study. Due to its naturalistic design, patients could have received other medications, including other antipsychotics.

Information was collected on sociodemographic and clinical characteristics, as well as on disease severity using the Clinical Global Impression (CGI) severity scale for schizophrenia, on daily functioning and disability with the World Health Organization Disability Assessment Schedule (WHODAS 2.0), and on addiction severity using 
the Severity of Dependence Scale (SDS) before starting treatment with LAI aripiprazole. The CGI severity scale, WHODAS 2.0 and SDS scores were also recorded at 3 and 6 months after treatment initiation.

The CGI severity scale for schizophrenia is an instrument that was devised to evaluate the severity and treatment response among patients with a diagnosis of schizophrenia [31]. It comprises five items based on a 7-point Likert scale that focus on positive, negative, depressive, cognitive, and overall symptom severity. This scale is considered a simple and reliable measure to evaluate the clinical status and course of the disease during routine clinical practice [32]. The WHODAS 2.0 evaluates six domains of functioning as experienced in the previous 30 days: mobility, self-care, life activities, understanding and communicating, interpersonal interactions, and participation in society [33]. This 12-item instrument assesses each domain with two items that are measured on a 3-point scale in which 1 indicates no disability and 2 and 3 indicate mild to moderate and severe to extreme disability, respectively. Therefore, the higher the score is, the greater the disability. We used the validated Spanish version of the WHODAS 2.0 [34]. The Severity of Dependence Scale (SDS) is a reliable and valid 5-item screening instrument that provides a score indicating the severity of dependence on several types of substances [35]. Each of the five items is scored on a 4-point scale (0-3). The total score is obtained through the sum of the ratings of the 5 items. The higher the score is, the higher the severity of substance dependence. We used the validated Spanish version of the SDS [36, 37].

For the statistical analysis, quantitative variables were described with the mean and standard deviation, and qualitative variables were described with the absolute and relative frequencies. Changes after treatment initiation in the outcome measures were analyzed using a paired Student's $t$ test. Changes were considered statistically significant at $p<0.05$. All analyses were performed with $\operatorname{IBM}^{\circledR}$ SPSS $^{\circledR}$ Statistics Version 25 for the Mac OS.

\section{Results}

\subsection{Demographic and Clinical Characteristics}

A consecutive sample of 40 patients with a mean age of 38 years who were predominantly male and mostly single or divorced were included in the study (Table 1). The most frequent medical comorbidities were hepatitis (20\%) and HIV infection (10\%). Half of the patients had multiple episodes of schizophrenia, a majority were currently in partial remission, and over half were mildly to moderately ill, as evaluated with the CGI scale (Table 2). Thirty-two (80\%) of the patients had previous inpatient admissions, with a mean of 3.7 admissions. For the vast majority of patients, treatment with LAI aripiprazole was initiated at a dose of $400 \mathrm{mg}$ every 4 weeks. Many patients were prescribed other psychotropic medications, as well, most commonly benzodiazepines and antidepressants, while 9 (22.5\%) patients were also taking oral antipsychotics (six were taking quetiapine, two were taking olanzapine, and one was taking levomepromazine). Eighteen (45\%) patients were receiving psychotherapy, which consisted of individual sessions of cognitive behavioral guidance.

The most frequent current and lifetime SUD diagnoses involved tobacco, alcohol, cannabis or cocaine. Drug use was initiated at a mean age of 14-25 years for the different substances (Table 3). Very few patients received specific pharmacological treatment for the SUD (Table 2).

\subsection{Efficacy Results}

At the end of the follow-up, $31(77.5 \%)$ patients were receiving $400 \mathrm{mg} / 4$ weeks, $5(12.5 \%)$ were receiving $300 \mathrm{mg} / 4$ weeks, 3 (7.5\%) were receiving $400 \mathrm{mg} / 3$ weeks, and 1 patient (2.5\%) was receiving $400 \mathrm{mg} / 2$ weeks of LAI aripiprazole; 34 (85\%) patients were receiving other psychotropics, including 1 patient receiving an antipsychotic (quetiapine). Almost half of the patients were also receiving some kind of psychotherapy intervention.

Table 1 Sociodemographic characteristics and medical comorbidities

\begin{tabular}{lc}
\hline Characteristic & $N=40$ \\
\hline Age (years), mean (SD) & $37.7(9.9)$ \\
Sex (male) $[n(\%)]$ & $31(77.5)$ \\
Marital status $[n(\%)]$ & \\
Single/never married & $21(52.5)$ \\
Married/living with a partner & $12(30.0)$ \\
Divorced & $7(17.5)$ \\
Working status $[n(\%)]$ & \\
Active & $11(27.5)$ \\
Unemployed & $5(12.5)$ \\
Permanent disability & $13(32,5)$ \\
Retired & $6(15 \%)$ \\
Housewife & $1(2.5)$ \\
Other & $2(5.0)$ \\
Medical comorbidity $[n(\%)]$ & \\
Hepatitis & $8(20.0)$ \\
HIV infection & $4(10.0)$ \\
Hypertension & $2(5.0)$ \\
Obesity & $2(5.0)$ \\
Diabetes mellitus & $1(2.5)$ \\
Tuberculosis & $1(2.5)$ \\
Other & $7(17.5)$ \\
\hline
\end{tabular}

$H I V$ human immunodeficiency virus, $S D$ standard deviation 
Table 2 Psychiatric history and treatment

\begin{tabular}{|c|c|}
\hline Characteristic & $N=40$ \\
\hline \multicolumn{2}{|l|}{ Schizophrenia diagnosis (course specifiers) $[n(\%)]$} \\
\hline First episode, currently in partial remission & $9(22.5)$ \\
\hline Multiple episodes, currently in acute episode & $5(12.5)$ \\
\hline Multiple episodes, currently in partial remission & $20(50.0)$ \\
\hline Multiple episodes, currently in full remission & $4(10.0)$ \\
\hline Continuous & $1(2.5)$ \\
\hline Unspecified & $1(2.5)$ \\
\hline \multicolumn{2}{|l|}{ Previous admissions } \\
\hline Yes $[n(\%)]$ & $32(80.0)$ \\
\hline Total number, mean (SD) & $3.7(3.3)$ \\
\hline Number in previous year, mean (SD) & $0.8(0.9)$ \\
\hline WHODAS 2.0, total score & $57.5(8.2)$ \\
\hline \multicolumn{2}{|l|}{ CGI severity $[n(\%)]$} \\
\hline Normal, not ill & $0(0.0)$ \\
\hline Minimally ill & $5(12.5)$ \\
\hline Mildly ill & $10(25.0)$ \\
\hline Moderately ill & $13(32.5)$ \\
\hline Markedly ill & $6(15.0)$ \\
\hline Severely ill & $6(15.0)$ \\
\hline Among the most severely ill & $0(0.0)$ \\
\hline \multicolumn{2}{|l|}{ LAI aripiprazole: initial dose $[n(\%)]$} \\
\hline $400 \mathrm{mg} / 2$ weeks & $1(2.5)$ \\
\hline $400 \mathrm{mg} / 3$ weeks & $3(7.5)$ \\
\hline $400 \mathrm{mg} / 4$ weeks & $33(82.5)$ \\
\hline $300 \mathrm{mg} / 4$ weeks & $3(7.5)$ \\
\hline \multicolumn{2}{|l|}{ Other psychotropics ${ }^{\mathrm{a}}[n(\%)]$} \\
\hline Any & $34(85.0)$ \\
\hline Antidepressants & $13(32.5)$ \\
\hline Lithium & $1(2.5)$ \\
\hline Benzodiazepines & $19(47.5)$ \\
\hline Oral antipsychotics & $9(22.5)$ \\
\hline Anticonvulsants & $11(27.5)$ \\
\hline \multicolumn{2}{|l|}{ SUD pharmacologic treatments $[n(\%)]$} \\
\hline Opioid agonists & $3(7.5)$ \\
\hline Naltrexone & $1(2.5)$ \\
\hline Nalmefene & $3(7.5)$ \\
\hline Disulfiram & $2(5.0)$ \\
\hline Varenicline & $1(2.5)$ \\
\hline Psychotherapy $[n(\%)]$ & $18(45.0)$ \\
\hline
\end{tabular}

$S D$ standard deviation

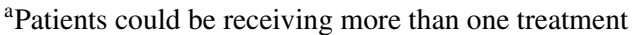

Overall, treatment with LAI aripiprazole was associated with a significant improvement in the psychopathological symptoms as evaluated with the five CGI severity scales (Fig. 1). Across all scales, a reduction of over $30 \%$ in the CGI severity score was observed after 6 months of treatment with LAI aripiprazole. The mean (standard deviation) score of the WHODAS 2.0 was significantly reduced
Table 3 Substance use disorder characterization

\begin{tabular}{|c|c|}
\hline Characteristic $^{\mathrm{a}}$ & $N=40$ \\
\hline \multicolumn{2}{|l|}{ Tobacco } \\
\hline Lifetime $[n(\%)]$ & $36(90.0)$ \\
\hline Current $[n(\%)]$ & $35(87.5)$ \\
\hline Age of onset (years), mean (SD) & $14.3(1.5)$ \\
\hline \multicolumn{2}{|l|}{ Alcohol } \\
\hline Lifetime $[n(\%)]$ & $26(65.0)$ \\
\hline Current $[n(\%)]$ & $16(40.0)$ \\
\hline Age of onset (years), mean (SD) & $15.6(2.6)$ \\
\hline \multicolumn{2}{|l|}{ Caffeine } \\
\hline Lifetime $[n(\%)]$ & $11(27.5)$ \\
\hline Current $[n(\%)]$ & $11(27.5)$ \\
\hline Age of onset (years), mean (SD) & $15.9(2.5)$ \\
\hline \multicolumn{2}{|l|}{ Cannabis } \\
\hline Lifetime $[n(\%)]$ & $26(65.0)$ \\
\hline Current $[n(\%)]$ & $17(42.5)$ \\
\hline Age of onset (years), mean (SD) & $16.0(3.4)$ \\
\hline \multicolumn{2}{|l|}{ Opioids (heroin) } \\
\hline Lifetime $[n(\%)]$ & $7(17.5)$ \\
\hline Current $[n(\%)]$ & $3(7.5)$ \\
\hline Age of onset (years), mean (SD) & $19.9(3.5)$ \\
\hline \multicolumn{2}{|l|}{ Opioids (methadone) } \\
\hline Lifetime $[n(\%)]$ & $2(5.0)$ \\
\hline Current $[n(\%)]$ & $1(2.5)$ \\
\hline Age of onset (years), mean (SD) & $24.5(0.7)$ \\
\hline \multicolumn{2}{|l|}{ Sedatives } \\
\hline Lifetime $[n(\%)]$ & $5(12.5)$ \\
\hline Current $[n(\%)]$ & $5(12.5)$ \\
\hline Age of onset (years), mean (SD) & $24.2(8.2)$ \\
\hline \multicolumn{2}{|l|}{ Cocaine } \\
\hline Lifetime $[n(\%)]$ & $18(45.0)$ \\
\hline Current $[n(\%)]$ & $9(22.5)$ \\
\hline Age of onset (years), mean (SD) & $19.6(2.6)$ \\
\hline \multicolumn{2}{|l|}{ Pathological gambling } \\
\hline Lifetime $[n(\%)]$ & $4(10.0)$ \\
\hline Current $[n(\%)]$ & $1(2.5)$ \\
\hline Age of onset (years), mean (SD) & $25.2(2.4)$ \\
\hline
\end{tabular}

$S D$ standard deviation

${ }^{a}$ Patients could exhibit more than disorder

from $57.6(8.2)$ at treatment initiation to 42.3 (4.3) after 6 months of treatment $(p<0.001)$. The reductions in the scores of the CGI scales and WHODAS 2.0 were statistically significant at month 3 .

Regarding the SUDs, 4 of the 9 patients with a cocaine use disorder and 13 of the 16 patients with an alcohol use disorder at baseline were still consuming at 6 months of follow-up. In addition, all 3 patients with a heroin use disorder were abstinent at the end of the follow-up period (Fig. 2a). The only group of addictions that showed a 


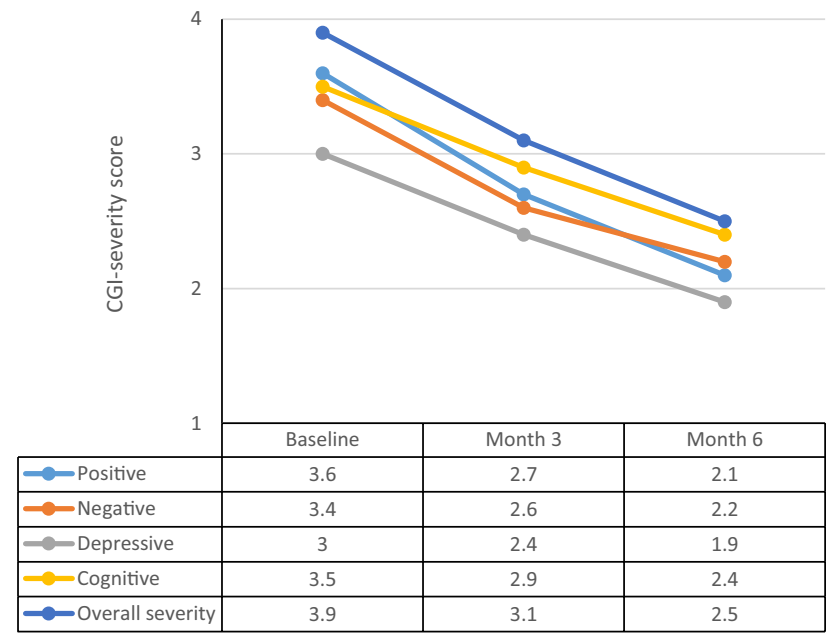

Fig. 1 Change in the Clinical Global Impression severity scores since treatment initiation. CGI severity scores range from 1 to $7 ; Y$ axis values represent scores 1-4 to improve the visibility of the data. All changes from baseline to month 3 and month 6 for all scales were statistically significant $(p<0.001)$

significant reduction in the severity of the dependence were the subgroups of alcohol (from a score [SD] of 10.6 [3.9]-8.9 [3.2]) and cocaine use disorders (from a score [SD] of 11.2 [4.9]-8.4 [3.5]) (Fig. 2b).

\section{Discussion}

The results of this observational retrospective study suggest that once-monthly LAI aripiprazole is efficacious for managing psychotic symptoms in patients with schizophrenia with coexisting SUDs. In addition, in psychotic patients with an alcohol or cocaine use disorder, LAI aripiprazole could be useful for reducing the severity of the use disorder and eventually achieving abstinence.

Once-monthly LAI aripiprazole was associated with a reduction in symptoms of schizophrenia, as shown by the observed significant changes in all of the CGI severity schizophrenia subscales after 6 months of treatment. These reductions, albeit modest, were clinically relevant. Thus, the mean change from baseline in the CGI severity scores was more than 1 point for all symptoms, as well as in the overall severity, corresponding to more than a $30 \%$ decrease in all CGI severity scores. Moreover, disability also improved to a similar extent (i.e., a $27 \%$ reduction in the WHODAS 2.0 score), suggesting that this improvement in the symptoms of schizophrenia in these dually diagnosed patients is accompanied by an improvement in functioning. These results are difficult to put into perspective in terms of external evidence, since information on the use of LAI antipsychotics in patients with schizophrenia and a coexisting SUD is limited. In one of the few published reports, a
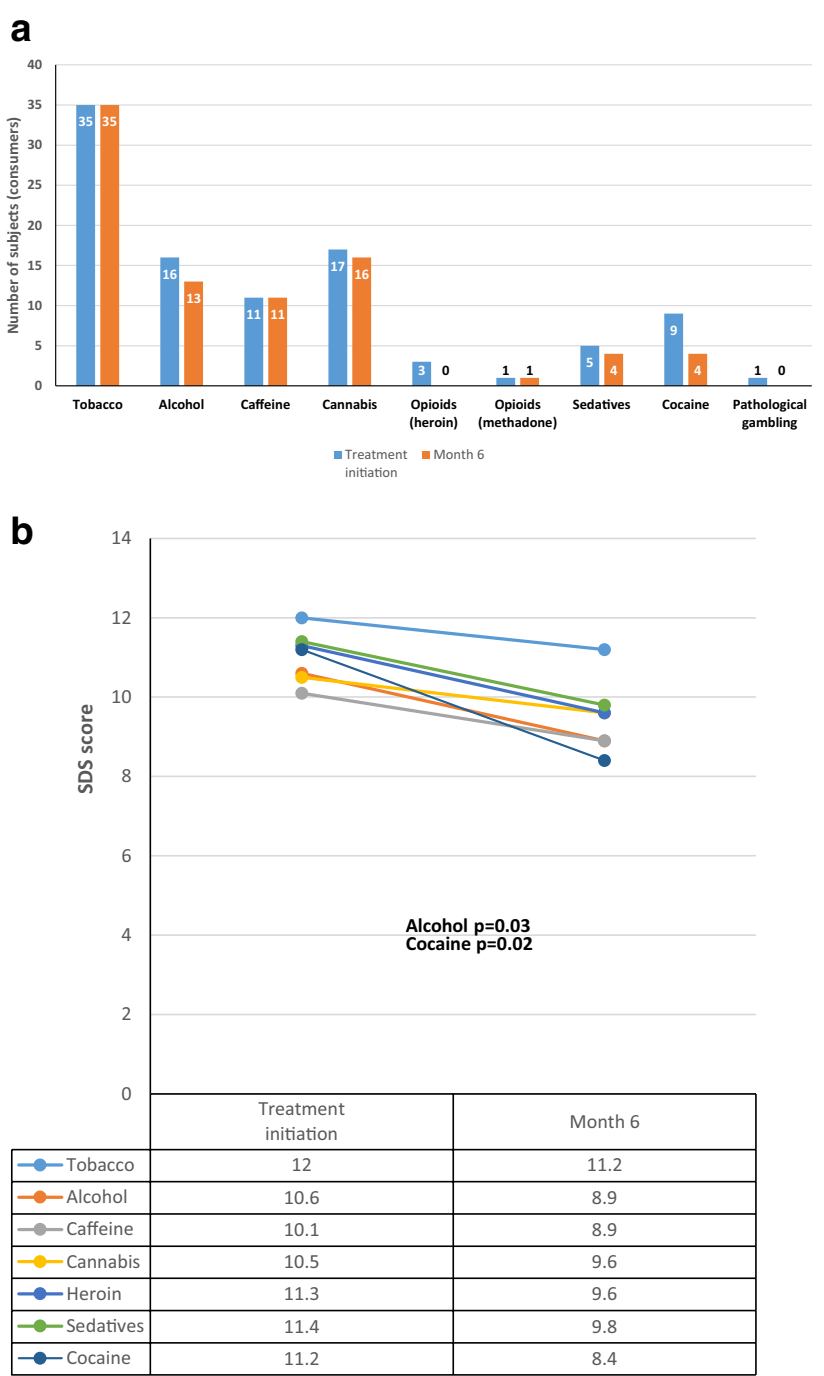

Fig. 2 Time course of substance use disorders* under treatment with long-acting injectable aripiprazole. a Number of consumers. b Course of severity of dependence (SDS). Asterisk patients could exhibit more than disorder

randomized clinical trial comparing the efficacy and safety of LAI and oral formulations of risperidone, no differences were found between the two formulations of risperidone in the improvement of psychopathological symptoms [38]. LAI risperidone has also been compared with zuclopenthixol in patients with schizophrenia and comorbid substance abuse in a randomized, open-label, 6-month study that reported a $34 \%$ reduction in the Positive and Negative Syndrome scale total score, an effect size that is almost identical to that observed in the CGI overall severity score here (i.e., a $36 \%$ reduction) [39]. A randomized, 1-year follow-up study comparing LAI aripiprazole with LAI paliperidone in patients with psychosis, mostly schizophrenia, and SUD reported a large effect of the change from baseline in the CGI severity score, from 5.9 to 2.4 for LAI aripiprazole and from 5.7 to 
2.6 for LAI paliperidone [29]. However, patients in the LAI aripiprazole group were much younger than those included in our study (a mean of $27 \mathrm{vs.} 38$ years old), and the number of previous hospitalizations was lower (a mean of $1.8 \mathrm{vs.} 3.7$ hospitalizations), suggesting that the patients in their study had a much less chronic disease. Considering these differences and the fact that their patients also exhibited a more severe symptoms of schizophrenia before starting treatment and a longer follow-up, it is not possible to compare the results of these studies.

LAI aripiprazole also showed a beneficial effect on some measures of substance use in patients with alcohol use disorder and especially in those with cocaine use disorder, with significant and clinically relevant reductions in the severity of the dependence. In addition, in the case of cocaine use disorder, a substantial number of patients achieved abstinence by the end of follow-up (i.e., from 9 patients who were consumers at treatment initiation to 4 patients by the end of follow-up). Previous studies of oral aripiprazole in patients with SUDs support these results. In a randomized placebocontrolled study, Moran et al. [21] showed that oral aripiprazole could delay relapse in recently abstinent cocaine users; however, somewhat unexpectedly, aripiprazole increased cocaine craving. In any case, the study was terminated early because of difficulties recruiting patients who met the abstinence criterion [21]. In a 12-week randomized pilot study in patients with cocaine dependence, oral aripiprazole was more efficacious than ropinirole in reducing cocaine use [40]. Specifically, in a short-term, double-blind randomized trial in patients with a dual diagnosis of schizophrenia and cocaine dependence, oral aripiprazole was as efficacious as perphenazine in the number of patients with cocaine-free urine samples and the frequency and duration of craving [27]. However, we must be cautious when interpreting these results and when suggesting the efficacy of LAI aripiprazole and other antipsychotics for the treatment of patients with schizophrenia and cocaine use disorder. Some laboratory studies have not supported the usefulness of aripiprazole for the management of cocaine use disorders [22, 24]. In addition, a systematic review of 14 placebo-controlled studies investigating the use of antipsychotics for cocaine dependence from the Cochrane Collaboration did not find significant differences in any of the outcome variables analyzed, including the number of patients using cocaine during treatment, continuous abstinence and craving [41], supporting the results of a previous meta-analysis on the use of antipsychotics for cocaine or psychostimulant use disorder [42]. Focusing on patients with a dual disorder diagnosis, another systematic review concluded that the efficacy of antipsychotics for cocaine dependence in patients with schizophrenia has not been robustly demonstrated [43]. Although the sample size precludes any conclusion, it is worthy to mention that the three patients with heroin use disorder at baseline achieved abstinence at the end of the follow-up.

Our results regarding the impact of once-monthly LAI aripiprazole on alcohol use disorder were also encouraging, showing a significant reduction in symptom severity and stopping alcohol use in some cases. As is the case for cocaine dependence, the results for oral aripiprazole treatment in patients with alcohol dependence are mixed [18, 25, 44]. Martinotti et al. [45], in a narrative review of the available evidence, stated that there is no conclusive evidence for the effects of aripiprazole on the prevention of craving or a reduction in alcohol consumption. The results for other antipsychotics do not support the efficacy of these medications for primary alcohol dependence [46]. Finally, the limited works investigating LAI aripiprazole in patients with schizophrenia and coexisting SUDs do not provide results for specific substance use disorders $[29,30]$.

It is also important to note that the Food and Drug Administration and other health authorities have issued a warning regarding the use of aripiprazole and the development of rare impulse control problems, including pathological gambling, binge-eating disorder, and hypersexuality [47]. While potent dopamine $\mathrm{D} 2$ receptor antagonist antipsychotics have been linked to elevated levels of substance dependence such as nicotine dependence in smokers with schizophrenia [48], in contrast, aripiprazole increases dopamine activity in the mesolimbic dopaminergic pathway, which is involved in the development of maladaptive behaviors, and has 5-HT1A partial agonist and 5-HT2A antagonist properties that may promote sexual activity; these actions could partially explain the occurrence of these impulse control disorders [49]. However, the trigger mechanism of addictive behavior is complex and cannot only be attributed to the pharmacodynamic effects of dopaminergic drugs. Individual vulnerabilities and environmental factors need to be considered in its occurrence [50]. In any case, this side effect is uncommon, and in our view, the benefits of enhancing dopamine activity in these dual disorders patients, through the D2 partial agonist properties of aripiprazole and its high D2 receptor affinity, to counteract psychopathological symptoms outweigh the risk of this side effect in this population with coexisting SUDs.

The use of antipsychotics is crucial for the treatment of patients with schizophrenia regardless of whether they have a co-occurrent SUD [12], and treatment with LAI may offer some advantages over oral formulations $[12,38]$ and is preferred by clinicians in routine clinical practice [51-53]; however, little is known about the efficacy of LAI antipsychotics for the management of dually diagnosed patients. In addition to its retrospective and uncontrolled design, our study has several limitations; these include the small sample size, especially for evaluating its efficacy in specific subgroups 
of SUDs; the allowed concomitant use of psychotropics; and the limited information available on outcomes such as sustained abstinence, which are more predictive of the longterm usefulness of this intervention for the management of SUDs. Despite its important limitations, our study suggests that once-monthly LAI aripiprazole retains its antipsychotic efficacy in patients with schizophrenia and a coexisting SUD and could be effective for the management of alcohol or cocaine use disorders in this population. These promising results should be confirmed by randomized clinical trials that include a long-term follow-up and an evaluation of the impact of the treatment on specific outcomes, such as sustained abstinence, a reduction in the severity of SUDs and the so-called "good functioning" (i.e., a composite measure encompassing a lack of substance use and no reported legal, psychological, family, or employment problems) [54].

Acknowledgements The author would like to thank Fernando RicoVillademoros MD (COCIENTE S.L., Madrid, Spain) for his editorial assistance in the preparation of this manuscript; his assistance was funded by the Sociedad Española de Patología Dual (Spanish Society on Dual Disorders).

Data Availability The datasets generated during and/or analyzed during the current study are available from the corresponding author on reasonable request.

\section{Compliance with Ethical Standards}

Funding The study was supported by an unrestricted educational grant from Otsuka/Lundbeck to the Fundación de Patología Dual (Madrid, Spain).

Conflict of Interest NS has received speaker honorarium from Lundbeck, Shire, Exeltis, Rubio, Indivior, and Adamed: IB-V has received Speaker honorarium from Servier, Exeltis, and Lundbeck; PV has received speaker-travel honorarium from Gilead, MSD, Abbvie, and Rubió. JM-R is advisory board member for Shire and has received speaker honorarium from Lundbeck, Janssen, and Shire; CP-T has received speaker honorarium from Janssen and Servier, and travel grants from Lundbeck and Qualigen; JCA has received travel grants from Lundbeck and Janssen; LG-L has received speaker honorarium from Janssen; MdM has received speaker-travel honorarium from Janssen, Qualigen, Lundbeck; FA declares no conflict of interest related with this manuscript.

Ethical Approval The study was revised and approved by the Ethics Committee of the Hospital General Universitario Gregorio Marañón (Madrid, Spain).

Informed Consent Informed consent was obtained from all individual participants included in the study.

Open Access This article is licensed under a Creative Commons Attribution-NonCommercial 4.0 International License, which permits any non-commercial use, sharing, adaptation, distribution and reproduction in any medium or format, as long as you give appropriate credit to the original author(s) and the source, provide a link to the Creative Commons licence, and indicate if changes were made. The images or other third party material in this article are included in the article's Creative Commons licence, unless indicated otherwise in a credit line to the material. If material is not included in the article's Creative Commons licence and your intended use is not permitted by statutory regulation or exceeds the permitted use, you will need to obtain permission directly from the copyright holder.To view a copy of this licence, visit http://creativecommons.org/licenses/by-nc/4.0/.

\section{References}

1. Hunt GE, Large MM, Cleary M, Lai HMX, Saunders JB. Prevalence of comorbid substance use in schizophrenia spectrum disorders in community and clinical settings, 1990-2017: systematic review and meta-analysis. Drug Alcohol Depend. 2018;191:234-58.

2. de Leon J, Diaz FJ. A meta-analysis of worldwide studies demonstrates an association between schizophrenia and tobacco smoking behaviors. Schizophr Res. 2005;76:135-57.

3. Desai RA, Potenza MN. A cross-sectional study of problem and pathological gambling in patients with schizophrenia/schizoaffective disorder. J Clin Psychiatry. 2009;70:1250-7.

4. Haywood TW, Kravitz HM, Grossman LS, Cavanaugh JL, Davis JM, Lewis DA. Predicting the "revolving door" phenomenon among patients with schizophrenic, schizoaffective, and affective disorders. Am J Psychiatry. 1995;152:856-61.

5. Swartz MS, Swanson JW, Hiday VA, Borum R, Wagner HR, Burns BJ. Violence and severe mental illness: the effects of substance abuse and nonadherence to medication. Am J Psychiatry. 1998;155:226-31.

6. Potvin S, Sepehry AA, Stip E. A meta-analysis of negative symptoms in dual diagnosis schizophrenia. Psychol Med. 2006;36:431-40.

7. Potvin S, Sepehry AA, Stip E. Meta-analysis of depressive symptoms in dual-diagnosis schizophrenia. Aust N Z J Psychiatry. 2007;41:792-9.

8. Potvin S, Blanchet P, Stip E. Substance abuse is associated with increased extrapyramidal symptoms in schizophrenia: a metaanalysis. Schizophr Res. 2009;113:181-8.

9. Kuepper R, van Os J, Lieb R, Wittchen HU, Hofler M, Henquet C. Continued cannabis use and risk of incidence and persistence of psychotic symptoms: 10 year follow-up cohort study. BMJ. 2011;342:d738.

10. Schmidt LM, Hesse M, Lykke J. The impact of substance use disorders on the course of schizophrenia-a 15-year follow-up study: dual diagnosis over 15 years. Schizophr Res. 2011;130:228-33.

11. Foglia E, Schoeler T, Klamerus E, Morgan K, Bhattacharyya $S$. Cannabis use and adherence to antipsychotic medication: a systematic review and meta-analysis. Psychol Med. 2017;47:1691-705.

12. Crockford D, Addington D. Canadian schizophrenia guidelines: schizophrenia and other psychotic disorders with coexisting substance use disorders. Can J Psychiatry. 2017;62:624-34.

13. Hasan A, Falkai P, Wobrock T, Lieberman J, Glenthøj B, Gattaz WF, Thibaut F, Möller HJ, WFSBP Task Force on Treatment Guidelines for Schizophrenia. World Federation of Societies of Biological Psychiatry (WFSBP) Guidelines for Biological Treatment of Schizophrenia. Part 3: update 2015 Management of special circumstances: depression, suicidality, substance use disorders and pregnancy and lactation. World J Biol Psychiatry. 2015;16:142-70.

14. McEvoy JP, Freudenreich O, Levin ED, Rose JE. Haloperidol increases smoking in patients with schizophrenia. Psychopharmacology. 1995;119:124-6. 
15. Di Sciascio G, Riva MA. Aripiprazole: from pharmacological profile to clinical use. Neuropsychiatr Dis Treat. 2015;11:2635-47.

16. Vergne DE, Anton RF. Aripiprazole: a drug with a novel mechanism of action and possible efficacy for alcohol dependence. CNS Neurol Disord: Drug Targets. 2010;9:50-4.

17. Ribeiro ELA, de Mendonca LT, Vieira MEB, Storpirtis S, Aguiar PM. Efficacy and safety of aripiprazole for the treatment of schizophrenia: an overview of systematic reviews. Eur J Clin Pharmacol. 2018;74:1215-33.

18. Anton RF, Kranzler H, Breder C, Marcus RN, Carson WH, Han J. A randomized, multicenter, double-blind, placebo-controlled study of the efficacy and safety of aripiprazole for the treatment of alcohol dependence. J Clin Psychopharmacol. 2008;28:5-12.

19. Voronin K, Randall P, Myrick H, Anton R. Aripiprazole effects on alcohol consumption and subjective reports in a clinical laboratory paradigm-possible influence of self-control. Alcohol Clin Exp Res. 2008;32:1954-61.

20. Meini M, Moncini M, Cecconi D, Cellesi V, Biasci L, Simoni G, Ameglio M, Pellegrini M, Forgione RN, Rucci P. Aripiprazole and ropinirole treatment for cocaine dependence: evidence from a pilot study. Curr Pharm Des. 2011;17:1376-83.

21. Moran LM, Phillips KA, Kowalczyk WJ, Ghitza UE, Agage DA, Epstein DH, Preston KL. Aripiprazole for cocaine abstinence: a randomized-controlled trial with ecological momentary assessment. Behav Pharmacol. 2017;28:63-73.

22. Lofwall MR, Nuzzo PA, Campbell C, Walsh SL. Aripiprazole effects on self-administration and pharmacodynamics of intravenous cocaine and cigarette smoking in humans. Exp Clin Psychopharmacol. 2014;22:238-47.

23. Lile JA, Stoops WW, Hays LR, Rush CR. The safety, tolerability, and subject-rated effects of acute intranasal cocaine administration during aripiprazole maintenance II: increased aripipirazole dose and maintenance period. Am J Drug Alcohol Abuse. 2008;34:721-9.

24. Haney M, Rubin E, Foltin RW. Aripiprazole maintenance increases smoked cocaine self-administration in humans. Psychopharmacology. 2011;216:379-87.

25. Haass-Koffler CL, Goodyear K, Zywiak WH, Leggio L, Kenna GA, Swift RM. Comparing and combining topiramate and aripiprazole on alcohol-related outcomes in a human laboratory study. Alcohol Alcohol. 2018;53:268-76.

26. Han DH, Kim SM, Choi JE, Min KJ, Renshaw PF. Adjunctive aripiprazole therapy with escitalopram in patients with co-morbid major depressive disorder and alcohol dependence: clinical and neuroimaging evidence. J Psychopharmacol. 2013;27:282-91.

27. Beresford T, Buchanan J, Thumm EB, Emrick C, Weitzenkamp $\mathrm{D}$, Ronan PJ. Late reduction of cocaine cravings in a randomized, double-blind trial of aripiprazole vs perphenazine in schizophrenia and comorbid cocaine dependence. J Clin Psychopharmacol. 2017;37:657-63.

28. Wilson RP, Bhattacharyya S. Antipsychotic efficacy in psychosis with co-morbid cannabis misuse: a systematic review. J Psychopharmacol. 2016;30:99-111.

29. Cuomo I, Kotzalidis GD, de Persis S, Piacentino D, Perrini F, Amici E, De Filippis S. Head-to-head comparison of 1-year aripiprazole long-acting injectable (LAI) versus paliperidone LAI in comorbid psychosis and substance use disorder: impact on clinical status, substance craving, and quality of life. Neuropsychiatr Dis Treat. 2018;14:1645-56.

30. Huerta DH, Sanchez EBA, Garcia CAC, Viorreta RT. 17 D2 receptor partial agonists in dual disorders: use of aripiprazole in psychotic disorder and comorbid substance use disorder. CNS Spectr. 2019;24:181-2.
31. Haro JM, Kamath SA, Ochoa S, Novick D, Rele K, Fargas A, Rodriguez MJ, Rele R, Orta J, Kharbeng A, Araya S, Gervin M, Alonso J, Mavreas V, Lavrentzou E, Liontos N, Gregor K, Jones PB. The clinical global impression-schizophrenia scale: a simple instrument to measure the diversity of symptoms present in schizophrenia. Acta Psychiatr Scand Suppl. 2003;107:16-23.

32. Pinna F, Deriu L, Diana E, Perra V, Randaccio RP, Sanna L, Tusconi M, Carpiniello B. Clinical global impression-severity score as a reliable measure for routine evaluation of remission in schizophrenia and schizoaffective disorders. Ann Gen Psychiatry. 2015; $14: 6$.

33. World Health Organization. Measuring health and disability: manual for who disability assessment schedule WHODAS 2.0. Geneva: WHO Press; 2010.

34. Vazquez-Barquero JL, Bourgon EV, Castanedo SH, Saiz J, Uriarte M, Morales F, Gaite L, Herran A, Ustun TB. Spanish version of the new World Health Organization Disability Assessment Schedule II (WHO-DAS-II): initial phase of development and pilot study. Cantabria disability work group. Actas Esp Psiquiatr. 2000;28:77-87.

35. Gossop M, Darke S, Griffiths P, Hando J, Powis B, Hall W, Strang J. The severity of dependence scale (SDS): psychometric properties of the SDS in English and Australian samples of heroin, cocaine and amphetamine users. Addiction. 1995;90:607-14.

36. Gonzalez-Saiz F, de Las CC, Barrio G, Domingo-Salvany A. Spanish version of the severity of dependence scale (SDS). Med Clin (Barc). 2008;131:797-8.

37. Gonzalez-Saiz F, Lozano OM, Ballesta R, Silva T, Brugal MT, Bilbao I, Barrio G, Domingo-Salvany A, Bravo MJ, De la Fuente L, Del Proyecto IG. Validity of the Severity of Dependence Scale (SDS) construct applying the item response theory to a non-clinical sample of heroin users. Subst Use Misuse. 2008;43:919-35.

38. Green AI, Brunette MF, Dawson R, Buckley P, Wallace AE, Hafez H, Herz M, Narasimhan M, Noordsy DL, O'Keefe C, Sommi RW, Steinbook RM, Weeks M. Long-acting injectable vs oral risperidone for schizophrenia and co-occurring alcohol use disorder: a randomized trial. J Clin Psychiatry. 2015;76:1359-65.

39. Rubio G, Martinez I, Ponce G, Jimenez-Arriero MA, LopezMunoz F, Alamo C. Long-acting injectable risperidone compared with zuclopenthixol in the treatment of schizophrenia with substance abuse comorbidity. Can J Psychiatry. 2006;51:531-9.

40. Meini M, Moncini M, Cecconi D, Cellesi V, Biasci L, Simoni G, Ameglio M, Pellegrini M, Forgione RN, Rucci P. Safety, tolerability, and self-rated effects of aripiprazole and ropinirole treatment for cocaine dependence: a pilot study. Am J Addict. 2011;20:179-80.

41. Indave BI, Minozzi S, Pani PP, Amato L. Antipsychotic medications for cocaine dependence. Cochrane Database Syst Rev. 2016;3:CD006306.

42. Kishi T, Matsuda Y, Iwata N, Correll CU. Antipsychotics for cocaine or psychostimulant dependence: systematic review and meta-analysis of randomized, placebo-controlled trials. J Clin Psychiatry. 2013;74:e1169-80.

43. Sabioni P, Ramos AC, Galduroz JC. The effectiveness of treatments for cocaine dependence in schizophrenic patients: a systematic review. Curr Neuropharmacol. 2013;11:484-90.

44. Martinotti G, Di Nicola M, Di Giannantonio M, Janiri L. Aripiprazole in the treatment of patients with alcohol dependence: a double-blind, comparison trial vs. naltrexone. J Psychopharmacol. 2009;23:123-9.

45. Martinotti G, Orsolini L, Fornaro M, Vecchiotti R, De Berardis D, Iasevoli F, Torrens M, Di Giannantonio M. Aripiprazole for relapse prevention and craving in alcohol use disorder: current evidence and future perspectives. Expert Opin Investig Drugs. 2016;25:719-28. 
46. Kishi T, Sevy S, Chekuri R, Correll CU. Antipsychotics for primary alcohol dependence: a systematic review and meta-analysis of placebo-controlled trials. J Clin Psychiatry. 2013;74:e642-54.

47. Food and Drug Administration. FDA drug safety communication: FDA warns about new impulse-control problems associated with mental health drug aripiprazole (abilify, abilify maintena, aristada). 2016. https://www.fda.gov/drugs/drugsafety/ucm498662. htm. Accessed 15 April 2019.

48. Whitton AE, Green AI, Pizzagalli DA, Roth RM, Williams JM, Brunette MF. Potent dopamine D2 antagonists block the rewardenhancing effects of nicotine in smokers with schizophrenia. Schizophr Bull. 2019. https://doi.org/10.1093/schbul/sby 185 .

49. Etminan M, Sodhi M, Samii A, Procyshyn RM, Guo M, Carleton BC. Risk of gambling disorder and impulse control disorder with aripiprazole, pramipexole, and ropinirole: a pharmacoepidemiologic study. J Clin Psychopharmacol. 2017;37:102-4.

50. Grall-Bronnec M, Sauvaget A, Perrouin F, Leboucher J, Etcheverrigaray F, Challet-Bouju G, Gaboriau L, Derkinderen P, Jolliet P, Victorri-Vigneau C. Pathological gambling associated with aripiprazole or dopamine replacement therapy: do patients share the same features? A review. J Clin Psychopharmacol. 2016;36:63-70.
51. Clerici M, de Bartolomeis A, De Filippis S, Ducci G, Maremmani I, Martinotti G, Schifano F. Patterns of management of patients with dual disorder (psychosis) in Italy: a survey of psychiatrists and other physicians focusing on clinical practice. Front Psychiatry. 2018;9:575.

52. Ostuzzi G, Mazzi MA, Terlizzi S, Bertolini F, Aguglia A, Bartoli F, Bortolaso P, Callegari C, Caroleo M, Carrà G, Corbo M, D’Agostino A, Gastaldon C, Lucii C, Magliocco F, Martinotti G, Nosé M, Ostinelli EG, Papola D, Piccinelli MP, Piccoli A, Purgato M, Tabacchi T, Turrini G, Ruggeri M, Barbui C, STAR Network Investigators. Factors associated with first- versus second-generation long-acting antipsychotics prescribed under ordinary clinical practice in Italy. PLoS One. 2018;13:e0201371.

53. Poloni N, Ielmini M, Caselli I, Lucca G, Gasparini A, Gasparini A, Lorenzoli G, Callegari C. Oral antipsychotic versus long-acting injections antipsychotic in schizophrenia spectrum disorder: a mirror analysis in a real-world clinical setting. Psychopharmacol Bull. 2019;49:17-27.

54. McCann DJ, Ramey T, Skolnick P. Outcome measures in medication trials for substance use disorders. Curr Treat Options Psychiatry. 2015;2:113-21. 